\title{
High-Frequency Stimulation of the Subthalamic Nucleus Potentiates L-DOPA-Induced Neurochemical Changes in the Striatum in a Rat Model of Parkinson's Disease
}

\author{
Abid Oueslati, ${ }^{1}$ Véronique Sgambato-Faure, ${ }^{2,3}$ Christophe Melon, ${ }^{1}$ Philippe Kachidian, ${ }^{1}$ Paolo Gubellini, ${ }^{1}$ \\ Mohammed Amri, ${ }^{4}$ Lydia Kerkerian-Le Goff, ${ }^{1}$ and Pascal Salin ${ }^{1}$ \\ ${ }^{1}$ Developmental Biology Institute of Marseille Luminy, Unité Mixte de Recherche 6216, Centre National de la Recherche Scientifique-Université de la \\ Méditerranée, 13402 Marseille cedex 20, France, ${ }^{2}$ Neurosciences Précliniques, Institut National de la Santé et de la Recherche Médicale U318, 38043 \\ Grenoble cedex, France, ${ }^{3}$ Dynamique des Réseaux Neuronaux, Institut National de la Santé et de la Recherche U704 -Université Joseph Fourier, 38041 \\ Grenoble Cedex 9, France, and ${ }^{4}$ Laboratoire de Physiologie de la Nutrition, Faculté des Sciences de Tunis, 2092 El Manar, Tunis, Tunisia
}

This study examined the cellular changes produced in the striatum by chronic L-DOPA treatment and prolonged subthalamic nucleus high-frequency stimulation (STN-HFS) applied separately, successively, or in association, in the 6-hydroxydopamine-lesioned rat model of Parkinson's disease (PD). Only animals showing severe L-DOPA-induced dyskinesias (LIDs) were included, and STN-HFS was applied for $5 \mathrm{~d}$ at an intensity efficient for alleviating akinesia without inducing dyskinesias. L-DOPA treatment alone induced FosB/ $\Delta$ FosB immunoreactivity, exacerbated the postlesional increase in preproenkephalin, reversed the decrease in preprotachykinin, and markedly increased mRNA levels of preprodynorphin and of the glial glutamate transporter GLT1, which were respectively decreased and unaffected by the dopamine lesion. STN-HFS did not affect per se the postlesion changes in any of these markers. However, when applied in association with L-DOPA treatment, it potentiated the positive modulation exerted by L-DOPA on all of the markers examined and tended to exacerbate LIDs. After $5 \mathrm{~d}$ of L-DOPA withdrawal, the only persisting drug-induced responses were an elevation in preprodynorphin mRNA levels and in the number of FosB/ $\Delta$ FosB-immunoreactive neurons. Selective additional increases in these two markers were measured when STN-HFS was applied subsequently to L-DOPA treatment. These data provide the first evidence that STN-HFS exacerbates the responsiveness of striatal cells to L-DOPA medication and suggest that STN-HFS acts specifically through an L-DOPAmodulated signal transduction pathway associated with LIDs in the striatum. They point to striatal cells as a primary site for the complex interactions between these two therapeutic approaches in PD and argue against a direct anti-dyskinetic action of STN-HFS.

Key words: deep brain stimulation; L-DOPA; dyskinesias; neuropeptides; FosB; GLT1; motor cortex

\section{Introduction}

Subthalamic nucleus high-frequency stimulation (STN-HFS) alleviates the L-DOPA-sensitive cardinal motor symptoms of Parkinson's disease (PD), with benefits comparable with those provided by L-DOPA, albeit with reduced motor complications (Benabid et al., 2000; Olanow, 2002). The mechanism of action of HFS remains uncertain and is suggested to be more complex than a simple inhibition of the target structure (for review, see McIntyre et al., 2004; Garcia et al., 2005; Perlmutter and Mink, 2006). However, STN-HFS has been shown to reverse dopamine

Received July 12, 2006; revised Jan. 25, 2007; accepted Jan. 27, 2007.

This work was supported by the Centre National de la Recherche Scientifique, Agence Nationale pour la Recherche (ANR-05-NEUR-013-03), the Action Concertéc Incitative (ACI) program from the Ministry of Research (ACI Grant 04 2 91, project NIC0057). A. Oueslati held a fellowship from “Comité d'Entente et de Coordination des Associations de Parkinsoniens" and from "Agence Universitaire de la Francophonie."

Correspondence should be addressed to Pascal Salin, Team "Cellular Interactions, Neurodegeneration and Neuroplasticity," Developmental Biology Institute of Marseille Luminy, Unité Mixte de Recherche 6216, Centre National de la Recherche Scientifique-Université de la Méditerranée, 31 chemin Joseph Aiguier, 13402 Marseille cedex 20, France. E-mail: salin@ibdml.univ-mrs.fr.

DOI:10.1523/JNEUROSCI.2949-06.2007

Copyright $\odot 2007$ Society for Neuroscience $\quad$ 0270-6474/07/272377-10\$15.00/0
(DA) lesion-induced functional alterations in the basal ganglia output structures in animal PD models, which provides cellular basis for its antiparkinsonian effects (Salin et al., 2002; Tai et al., 2003; Degos et al., 2005). To optimize PD treatment, postoperative adaptation of both stimulation parameters and L-DOPA dosage is required, given the complex interactions between these two treatments (Krack et al., 2002). STN-HFS has a dyskinesiainducing effect, which, however, progressively declines, allowing the increase in stimulation intensity, and it reduces L-DOPA requirement, which in turn reduces L-DOPA-induced dyskinesias (LIDs). Whereas considerable attention is paid to the effects of each treatment on the pathophysiological functioning of the basal ganglia, the neural substrate of their interactions remains unknown. Moreover, the possible impact of the long-term L-DOPA treatment received by PD patients before surgery on the responsiveness of basal ganglia components to subsequent STNHFS has not yet been investigated.

LIDs are generally agreed to result from the pulsatile stimulation of striatal dopamine receptors and downstream modifications in gene and protein expression (Cenci, 2002). Altered function and plasticity at striatal glutamatergic synapses might also be 
involved (Chase and Oh, 2000; Calon et al., 2003; Picconi et al., 2003; Robelet et al., 2004), underlying a pathological form of learning (Calon et al., 2000). The major molecular changes associated with LIDs in animal models and PD patients are the increase in preprodynorphin (PPDyn) mRNA levels in striatonigral neurons and the additional increase, above lesion-induced levels, in preproenkephalin (PPE) mRNA in striatopallidal neurons (Cenci et al., 1998; Henry et al., 1999, 2003; Calon et al., 2000, 2002; Zeng et al., 2000; Tel et al., 2002). The role of glutamatemediated mechanisms in these changes is supported by the experimental data showing that L-DOPA-induced overexpression of PPE is reduced by a glutamate antagonist (Perier et al., 2002) and is topographically superimposed to the increased expression of the glial glutamate transporter GLT1 (Lievens et al., 2001). Among the signal transduction pathways underlying the development of LIDs, striatal induction of the transcription factor $\Delta$ FosB is suggested to play a major role and to positively modulate PPDyn (Andersson et al., 1999). Little is known about the striatal effects of STN-HFS. Short-duration STN-HFS increases striatal glutamate extracellular levels (Bruet et al., 2003) and enhances dopamine release and metabolism (Bruet et al., 2001; Meissner et al., 2003; Lee et al., 2006). However, neither short duration nor prolonged STN-HFS significantly affects the dopamine lesion-induced increase in striatal PPE or preprotachykinin (PPT) mRNA expression (Salin et al., 2002; Bacci et al., 2004).

This study provides the first cellular substrates for the interaction between L-DOPA treatment and STN-HFS in a rat model of PD by showing that STN-HFS, which per se does not significantly modify striatal mRNA levels of PPE, PPDyn, PPT, and GLT1 nor induces FosB $/ \Delta$ FosB expression, selectively modulates the effects of dyskinesiogenic L-DOPA treatment on these markers. In addition, using cytochrome oxidase subunit I (CoI) mRNA levels as a marker, we provide evidence that STN-HFS has an impact on neuronal metabolic activity in layer $\mathrm{V}$ of motor cortical areas.

\section{Materials and Methods}

All experiments were performed on male Wistar rats weighing 180-200 g at the time of surgery and were in accordance with the European Communities Council Directive of November 24, 1986 (86/609/EEC). Six experimental groups of animals with the 6-hydroxydopamine (6OHDA) lesion were constituted to analyze the effects of L-DOPA and STN-HFS either separately, successively, or in combination: (1) lesion alone (6-OHDA); (2) L-DOPA treatment for $19 \mathrm{~d}$ (DOPA); (3) STNHFS for $5 \mathrm{~d}$ (HFS); (4) combined treatments, with STN-HFS being applied during the last $5 \mathrm{~d}$ of the $19 \mathrm{~d}$ L-DOPA treatment (DOPA plus HFS); (5) L-DOPA treatment for $14 \mathrm{~d}$ followed by STN-HFS for $5 \mathrm{~d}$ (DOPA/ HFS); (6) L-DOPA treatment for $14 \mathrm{~d}$ followed by a $5 \mathrm{~d}$ washout period (DOPA/washout). An additional group of naive rats without any surgery or treatment was used as control. All animals were killed $33 \mathrm{~d}$ after the 6-OHDA lesion. The behavioral and cellular analyses were performed after control of the extent of dopamine denervation and correct location of the stimulating electrode, as described below, on $n$ animals per group ( $n=5$ control; $n=4-6$ 6-OHDA; $n=6-9$ L-DOPA; $n=6-9$ HFS; $n=$ 5-7 DOPA plus HFS; $n=4$ DOPA/HFS; $n=5$ DOPA/washout).

\section{6-OHDA lesion}

Surgery was performed under Equitesin anesthesia $(4 \mathrm{ml} / \mathrm{kg})$. Animals received a unilateral injection of $10 \mu \mathrm{g}$ of 6-OHDA (Sigma-Aldrich, St. Quentin-Fallavier, France) dissolved in $5 \mu \mathrm{l}$ of $0.9 \%$ sterile $\mathrm{NaCl}$ containing $0.1 \%$ ascorbic acid, at the rate of $1 \mu \mathrm{l} / \mathrm{min}$, in the left SNc. The stereotaxic coordinates of the injection site were as follows: anteroposterior, $+2.2 \mathrm{~mm}$; lateral, $2.0 \mathrm{~mm}$; dorsoventral, $+3.3 \mathrm{~mm}$; with the incisor bar at $+5.0 \mathrm{~mm}$ above the interaural plane according to the rat stereotaxic atlas by De Groot (1959).

\section{Pharmacological treatment}

L-DOPA treatment consisted of two intraperitoneal injections per day at $12 \mathrm{~h}$ intervals, over $19 \mathrm{~d}$ for DOPA and DOPA plus HFS groups and over $14 \mathrm{~d}$ for DOPA/washout and DOPA/HFS groups, of $25 \mathrm{mg} / \mathrm{kg}$ L-DOPA and $12.5 \mathrm{mg} / \mathrm{kg}$ benserazide (Sigma-Aldrich) dissolved in $0.9 \% \mathrm{NaCl}$. The DOPA and DOPA plus HFS groups were killed $12 \mathrm{~h}$ after the last injection.

\section{Electrode implantation and chronic STN-HFS}

Ten days after the 6-OHDA lesion, the three groups of rats to be treated by STN-HFS were unilaterally implanted with one electrode for deep brain stimulation in the ipsilateral STN. As described previously (Bacci et al., 2004), the electrode was formed by two parallel platinum iridium wires insulated with Teflon and bared at the extremity at a length of 500 $\mu \mathrm{m}$ (diameter of each wire: $140 \mu \mathrm{m}$ insulated, $76 \mu \mathrm{m}$ bare). The distance between the two wires was $\sim 500 \mu \mathrm{m}$. The electrode was implanted so that the two wires were placed in the anteroposterior axis, and the bared part of each wire was covering the STN extent in depth. The stereotaxic coordinates were taken averaging interaural and bregma coordinates (Paxinos and Watson, 1986); from bregma, they were as follows: anteroposterior, $-3.8 \mathrm{~mm}$ (taken at equidistance of the two wires); lateral, 2.4 $\mathrm{mm}$; dorsoventral, $-8.1 \mathrm{~mm}$ from the dura. STN-HFS was applied continuously for $5 \mathrm{~d}$ on freely moving rats and delivered by a pulse generator/ stimulator and a stimulus isolation unit (P2MP, Marseille, France), which gave rectangular current pulses. The frequency was set at $130 \mathrm{~Hz}$ and the pulse width at $80 \mu$ s over the stimulation period for all of the stimulated animals. To avoid tissue damage, the intensity was set at 80 $\mu \mathrm{A}$, which was about twofold below the intensity evoking dyskinetic movements of the contralateral forelimb. Animals treated by STN-HFS were killed immediately after turning off the stimulation.

\section{Analysis of motor behavior}

Animals with the dopamine lesion alone and those with the lesion submitted to HFS were scored for akinesia of the contralateral forelimb by using the cylinder test, compared with control rats. The animals were not submitted to stimuli that could have enhanced their tendency to explore. In brief, animals were placed in a Plexiglas cylinder and, immediately after, videotaped for $30 \mathrm{~min}$ to examine the symmetry/asymmetry of their forepaw use during their explorative behavior in this new environment. The numbers of contacts made on the cylinder wall during this period with the ipsilateral paw, the contralateral paw, and both paws (double contacts) were determined and expressed as percentage of the total number of contacts.

For quantification of LIDs, also called abnormal involuntary movements (AIMs), animals of the L-DOPA and the L-DOPA plus HFS groups were videotaped for $2 \mathrm{~h}$ after the injection of L-DOPA at day 14 and day 19 of the chronic treatment, which corresponded respectively to the time point just before STN application (prestimulation) and the last day of HFS treatment. Individual animals were scored for 1 min every $10 \mathrm{~min}$, from 10 to $120 \mathrm{~min}$ after the injection of L-DOPA (12 monitoring periods of 1 min each) as reported previously (Robelet et al., 2004). Four subtypes of AIMs (i.e., locomotive, axial, orolingual, and forelimb dyskinesias) were evaluated, each rated using a scale from 0 to 4 defined by Cenci et al. (1998), and the sum of the four scores per time point was determined for each animal (maximal score, 16). Locomotive AIM was rated from the determination of the number of contralateral rotations per minute. Data are the means \pm SEM of the values determined from the $\mathrm{n}$ animals per group.

\section{Morphological studies}

Tissue preparation. All animals were killed by decapitation after $33 \mathrm{~d}$ postlesion survival time. The brains were quickly removed and then frozen in dry ice and stored at $-80^{\circ} \mathrm{C}$. Coronal ( $10 \mu \mathrm{m}$ thick) tissue sections were cut at $-20^{\circ} \mathrm{C}$ with a cryostat (CM3050; Leica, Nussloch, Germany) at striatal level between anteroposterior interaural coordinates 8.2 and 9.2 according to the atlas of Paxinos and Watson (1986). The sections were then mounted on SuperFrost Plus glass slides (Fisher Scientific, Elancourt, France) and stored at $-80^{\circ} \mathrm{C}$ until specific treatment.

Histological control of 6-OHDA lesion and electrode placement. The loss of DA terminals in the striatum was assessed as an index of the extent of 
the DA denervation by analysis of ${ }^{3} \mathrm{H}$-mazindol binding to DA uptake sites, as described previously (Salin et al., 2002). Briefly, brain sections were air dried and rinsed for $5 \mathrm{~min}$ in $50 \mathrm{~mm}$ Tris buffer with $120 \mathrm{~mm}$ $\mathrm{NaCl}$ and $5 \mathrm{~mm} \mathrm{KCl}$. They were then incubated for $40 \mathrm{~min}$ with $15 \mathrm{~nm}$ $\left[{ }^{3} \mathrm{H}\right]$-mazindol (specific activity, $17 \mathrm{Ci} / \mathrm{mm}$; NEN DuPont, Boston, MA) in $50 \mathrm{~mm}$ Tris buffer containing $300 \mathrm{~mm} \mathrm{NaCl}$ and $5 \mathrm{~mm} \mathrm{KCl}$ added with $0.3 \mathrm{~mm}$ desipramine to block the noradrenaline uptake sites. Sections were rinsed twice for $3 \mathrm{~min}$ in the Tris incubation buffer and for $10 \mathrm{~s}$ in distilled water and were air dried. ${ }^{3} \mathrm{H}$-sensitive photographic film (Kodak BioMax MS Film; Sigma, Steinheim, Germany) were apposed to the slides in $\mathrm{x}$-ray cassettes and exposed at room temperature for $21 \mathrm{~d}$. The levels of ${ }^{3} \mathrm{H}$-mazindol labeling were quantified by digitized image analysis from the film autoradiograms using a BIOCOM (Les Ulis, France) analysis system (Densirag). Gray levels were converted to optical densities (ODs) using external standards (calibrated density step tablet; Kodak, Rochester, NY). The mean OD value was determined from four sections per animal after subtracting the background signal measured on each section by scanning a corpus callosum area that is known to lack DA terminals. The location of the stimulating electrode in the STN of HFS groups was examined on cresyl-violet-stained sections: we considered the correct location when the anterior and posterior wires were both in the STN (see also Bacci et al., 2004). Animals showing a reduction of $<85 \%$ in ${ }^{3} \mathrm{H}$-mazindol binding or a misplaced electrode were not included in the experimental groups presented above.

\section{In situ hybridization histochemistry}

Probes were 43-48 mer synthetic oligonucleotides selected on the basis of the published sequence of PPE, PPT, PPDyn, GLT1, and CoI. Probes were $3^{\prime}$-end labeled by terminal deoxynucleotide transferase with ${ }^{35} \mathrm{~S}$ dATP $(1300 \mathrm{Ci} / \mathrm{mmol})$. The radiolabeled probes were then extracted on a Mini Spin Oligo Column (Roche, Indianapolis, IN).

All solutions used for in situ hybridization were treated with diethyl pyrocarbonate and autoclaved to avoid RNase degradation. Slidemounted sections were postfixed for $5 \mathrm{~min}$ in $3 \%$ paraformaldehyde. The sections were then incubated in prehybridization buffer containing $2 \times$ SSC and $1 \times$ Denhardt's solution. The sections were then acetylated for $10 \mathrm{~min}$ with $0.25 \%$ acetic anhydride in $0.1 \mathrm{M}$ triethanolamine and treated for $30 \mathrm{~min}$ in $0.1 \mathrm{M}$ Tris-glycine before being dehydrated in ethanol and air dried. Each section was covered with $35 \mu$ l of hybridization solution ( $4 \times$ SSC with $50 \%$ formamide, $10 \%$ dextran sulfate, $1 \times$ Denhardt's solution, $0.25 \mathrm{mg} / \mathrm{ml}$ Escherichia coli tRNA and $0.5 \mathrm{mg} / \mathrm{ml}$ sheared salmon sperm DNA) containing the radiolabeled probe (radioactivity level, $\sim 500,000 \mathrm{cpm}$ per section) and incubated overnight at $47^{\circ} \mathrm{C}$ in humid chambers. Sections were then rapidly rinsed in ice-cold $2 \times$ SSC and then treated successively for 10 and $40 \mathrm{~min}$ with $1 \times$ SSC at room temperature, $1 \times \operatorname{SSC}$ at $42^{\circ} \mathrm{C}$, and $0.1 \times$ SSC at $42^{\circ} \mathrm{C}$. Sections were then dehydrated in ethanol and air dried.

Striatal sections were apposed to Kodak Bio-Max MR-1 film, and exposure time was adjusted to avoid film saturation $(6-8 \mathrm{~d})$. Brain sections from control and experimental groups of animals were run together in the same experimental session and exposed side by side on the same autoradiographic film. Sections processed for cellular analysis of CoI mRNA levels were thereafter coated with GE Healthcare (Piscataway, NJ) LM1 autoradiographic emulsion and exposed at $4^{\circ} \mathrm{C}$ for 3 weeks. Exposed slides were developed in Kodak D-19 for 4 min at $13^{\circ} \mathrm{C}$ and counterstained with toluidine blue.

\section{Immunohistochemistry}

Brain sections were air dried and postfixed for $20 \mathrm{~min}$ in $4 \%$ paraformaldehyde and rinsed $(3 \times 5 \mathrm{~min})$ with PBS, $\mathrm{pH}$ 7.2. After incubation for 15 min in PBS with $\mathrm{H}_{2} \mathrm{O}_{2} 1 \%$ and for $30 \mathrm{~min}$ in PBS containing $10 \%$ bovine serum albumin (BSA) and $0.25 \%$ Triton X-100, sections were incubated in rabbit polyclonal IgG anti-FosB-like proteins (antibody sc-48, used at 1:1000 dilution; Santa Cruz Biotechnology, Santa Cruz, CA) with 2\% BSA and $0.25 \%$ Triton $\mathrm{X}-100$, for $2 \mathrm{~h}$ at room temperature and overnight at $4^{\circ} \mathrm{C}$. This antibody was directed against the N-terminal part of FosB and therefore able to recognize both FosB and its chronic isoforms such as $\Delta$ fosB-like proteins (Nestler et al., 1999; Perrotti et al., 2004). The sections were subsequently rinsed in BSA $2 \%$ and $5 \%$ and incubated for
$2 \mathrm{~h}$ with the biotinylated secondary antibody (diluted 1:200; BIOSPA, Milan, Italy) and then 45 min with an avidin-biotin-peroxidase complex (diluted 1:100 in PBS containing 0.25\% Triton X-100; Vector Laboratories, Burlingame, CA). Finally, the labeling was visualized with $0.05 \% 3-3$ ' diaminobenzidine (Sigma) and $0.04 \%$ hydrogen peroxidase.

\section{Data analysis}

For immunocytochemistry, striatal tissue sections were examined under a light microscope using a $4 \times$ objective connected to a COHU camera, and the digitized images were transferred to the screen of a video monitor with a resulting magnification of $150 \times$. Counts of FosB $/ \Delta$ FosB-positive neurons were performed on a $1 \mathrm{~mm}^{2}$ area in both the lateral and medial parts of the striatum ipsilateral to surgery. The mean number of labeled cells per square millimeter was determined from three sections per animal, and the data from all of the animals per group were averaged and expressed as means \pm SEM. For in situ hybridization histochemistry, levels of autoradiographic labeling were quantified by a computerized imaging system (BIOCOM). Analysis of striatal PPE, PPDyn, PPT, and GLT1 mRNA levels was performed from autoradiographic films and was restricted to the dorsal part of the structure, excluding the nucleus accumbens. Gray levels were converted to relative ODs by using standard internal curves. The background signal was determined for each section by scanning the corpus callosum (that lacked immunolabeling for the probes used) and subtracted from values obtained in the striatum on the same section. The mean OD was determined from three sections of each animal.

Analysis of CoI mRNA labeling was performed at the cellular level on emulsion-coated sections in layer $\mathrm{V}$ of motor cortical areas (Fr1, Fr2, HL). Sections were observed under dark-field epilumination with a $20 \times$ immersion objective of a microscope connected to a COHU camera, and the digitized images were transferred to the screen of a video monitor with a resulting magnification of $1000 \times$. Using the Visioscan image analysis software from BIOCOM, the number of silver grains per cell was estimated under polarized light by measuring OD with respect to a standard curve of a defined number of silver grains. Specific labeling was determined after subtracting autoradiographic background measured from the corpus callosum. A sampling of at least 60 labeled neurons $(>10$ grains) per section was quantified in three sections from each animal, and the mean number of silver grains per neuron was determined. For both film and cellular analyses, the data from all of the animals per condition were averaged and were expressed as percentage \pm SEM of the corresponding controls values.

Statistical analysis of data were performed using a one-way ANOVA followed by Student-Newman-Keuls test for multiple group comparison. Separate analysis was performed for the combined and the successive treatment conditions, the first one including the control, 6-OHDA, HFS, DOPA, and DOPA plus HFS groups, and the second the control, 6-OHDA, HFS, DOPA/washout, and DOPA/HFS groups. A significance of $p<0.05$ was required for rejection of the null hypothesis.

\section{Results}

Control of the 6-OHDA-induced denervation extent in the striatum and of the electrode location in STN

The 6-OHDA-lesioned animals, with or without subsequent L-DOPA and/or STN-HFS treatment, showed an almost complete loss of ${ }^{3} \mathrm{H}$-mazindol binding in the ipsilateral striatum (Fig. 1). Figure 2 illustrates the location of the two poles of the stimulation electrode in the anteroposterior extent of STN. Each pole was inside the central or lateral part of STN in the selected animals. No major tissue damage was observed in the structure after the $5 \mathrm{~d}$ of continuous stimulation.

\section{Behavioral observations}

Here, STN-HFS was applied in all of the animals at a fixed low intensity $(80 \mu \mathrm{A})$ not inducing any dyskinetic movement, both to ensure that only its antiparkinsonian action is assessed and to avoid tissue damage with prolonged application. However, within the $5 \mathrm{~min}$ before fixing the stimulation intensity, we ex- 


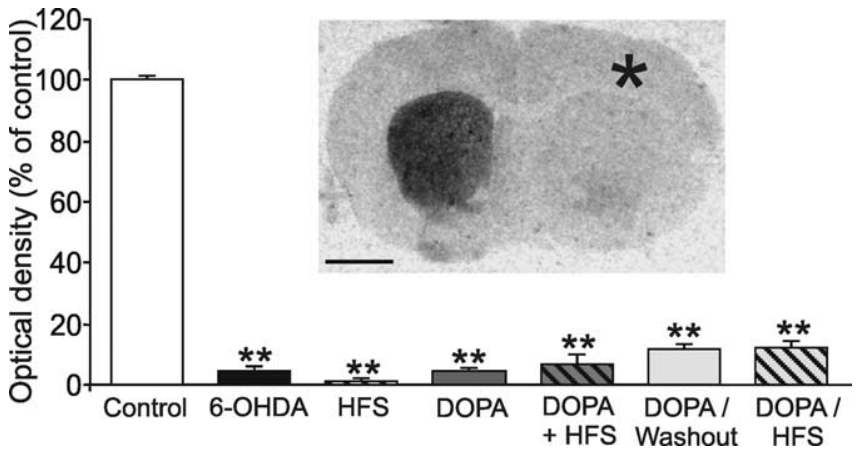

Figure 1. Illustrative autoradiographic image and quantitative analysis of ${ }^{3} \mathrm{H}$-mazindol binding, showing the extensive loss of dopamine terminals in the striatum ipsilateral to the lesion $\left(^{*}\right)$. The data presented in the graphs are the means \pm SEM of the optical density values determined from $n$ animals per condition (as defined in Material and Methods) and are expressed as percentages of control. Statistical comparisons are performed using a one-way ANOVA followed by Student-Newman-Keuls test. ${ }^{* *} p<0.01$ compared with control values. Scale bar, $2 \mathrm{~mm}$.

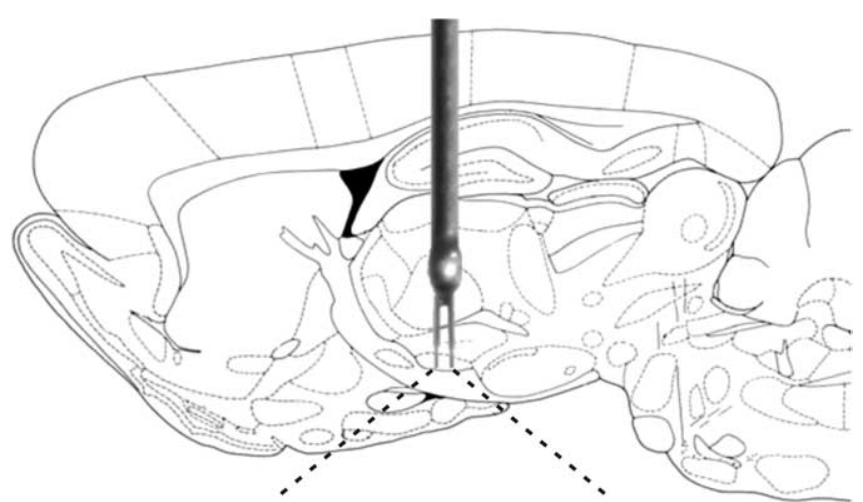

Ant. 5.40 Ant. 4.84
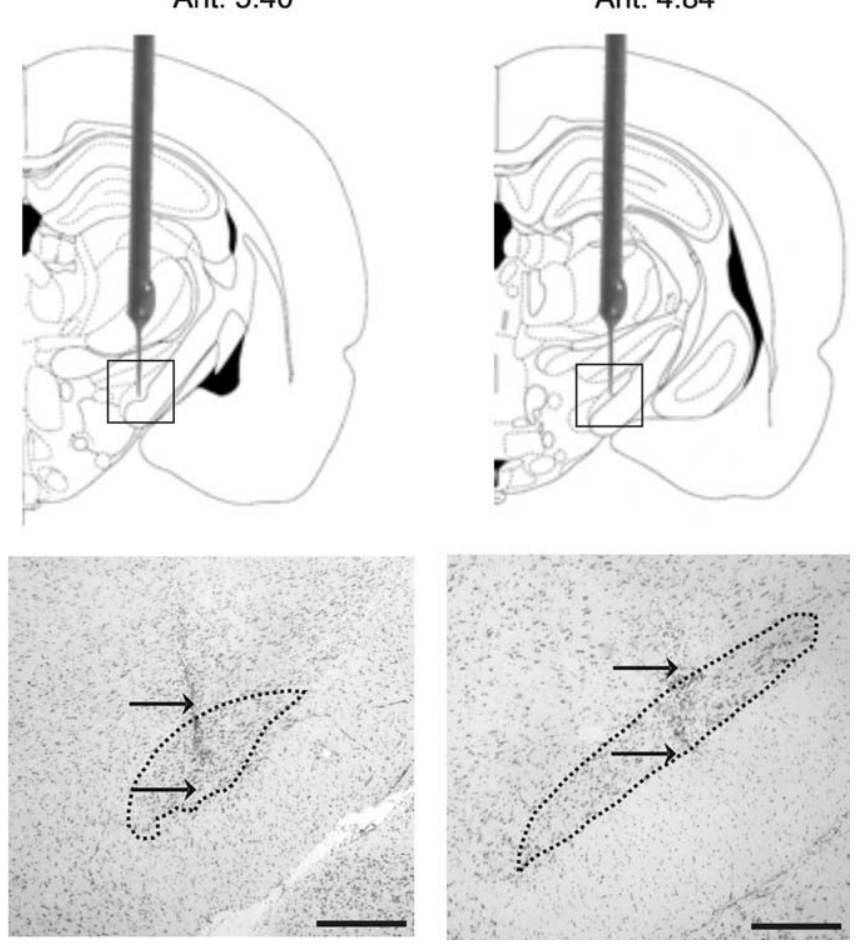

Figure 2. Schematic drawings (sagittal and coronal) and photomicrographs of cresyl violetstained coronal sections illustrating the location of the bipolar electrode for HFS in the anteroposterior (Ant.) extent of subthalamic nucleus (delineated by dotted lines). The arrows show the location of the bared electrode tips delivering HFS. Scale bar, $500 \mu \mathrm{m}$. amined for each rat the effects of progressively increasing the stimulation intensity. This evaluation was performed $12 \mathrm{~h}$ after the last injection of L-DOPA for the DOPA/HFS and DOPA + HFS groups, the latter receiving the next injection just afterward. As described previously (Salin et al., 2002; Bacci et al., 2004; Boulet et al., 2006), STN-HFS at increasing intensity induced per se a sequence of AIMs as follows: orofacial dyskinetic movements (from $\sim 110 \mu \mathrm{A}$ in our experimental conditions), plus dyskinetic movements of the contralateral forelimb (from $130 \mu \mathrm{A}$ ), plus strong contralateral bias in the head position, and finally contralateral rotation (from $170 \mu \mathrm{A}$ ). Therefore, the different subtypes of L-DOPA-induced AIMs can be induced sequentially by STN-HFS. This sequence, which was previously observed both in intact and hemiparkinsonian rats, was found here to also occur in lesioned rats treated with L-DOPA. Interestingly, we observed that the intensity of HFS required to produce this sequence of AIMs was significantly higher in the L-DOPAtreated versus untreated rats (threshold for forelimb dyskinesias, $136.5 \pm 4.8 \mu \mathrm{A}$ in 6 -OHDA group vs $173.5 \pm 7.9 \mu \mathrm{A}$ in DOPA group; $p<0.01$, Student's $t$ test). These data suggest that the dyskinesias-inducing effect of STN-HFS is only partly dependent on dopamine tone and is reduced by previous L-DOPA treatment, providing new evidence for an interaction between these treatments. Interestingly also, we observed in pilot experiments that the threshold for the induction of dyskinesias progressively increases with prolonged HFS. For instance, when maintaining a stimulation intensity initially producing forelimb dyskinesias, the dyskinesiogenic effect rapidly disappears. Moreover, after $2 \mathrm{~h}$ of HFS at low intensity, the threshold for induction of dyskinesias is substantially increased compared with that determined within the first minutes of stimulation, and in some cases is no more reached. These observations suggest that rapid adaptive mechanisms counterbalance the side effects of HFS.

\section{Effects of STN-HFS on akinesia}

In the cylinder test, control animals mostly used both forepaws $(57.7 \pm 3.4)$ to make contacts on the cylinder wall during their explorative behavior. In hemiparkinsonian rats, because of the akinesia of the contralateral forepaw, the proportion of double contacts was reduced by $\sim 70 \%(17.6 \pm 4.4$ in 6 -OHDA group; $17.3 \pm 7.4$ in the HFS group prestimulation; $p<0.01$ according to Student-Newman-Keuls test). HFS of the STN for $5 \mathrm{~d}$ efficiently relieved this deficit $(45.0 \pm 12.5)$, with a significant increase of double contacts compared with the lesion group $(p<$ 0.01 ) and no more significant difference versus control.

\section{Effects of STN-HFS on L-DOPA-induced dyskinesias}

To assess the effect of STN-HFS on LID, we measured the AIM score of DOPA plus HFS rats prestimulation, i.e., at day 14 of the L-DOPA treatment, and after $5 \mathrm{~d}$ of continuous stimulation corresponding to day 19 of L-DOPA, compared with the data obtained in the animals treated with L-DOPA alone at the same time points. We first examined the time course of the sum of the four AIM subtypes per monitoring period ( $1 \mathrm{~min}$ every $10 \mathrm{~min}$ ) over the $2 \mathrm{~h}$ after L-DOPA injection (Fig. $3 A$ ). No difference was noticeable between day 14 and day 19 in the animals with the L-DOPA treatment alone. In the DOPA plus HFS group, no difference was either observed between the scores at $5 \mathrm{~d}$ stimulation and prestimulation, except within the last monitoring periods, in which the stimulation values tended to be higher than the prestimulation scores. We then considered four time windows, each corresponding to the mean of three recording sessions: 10-30, $40-60,70-90$, and $100-120 \mathrm{~min}$, and we examined separately 


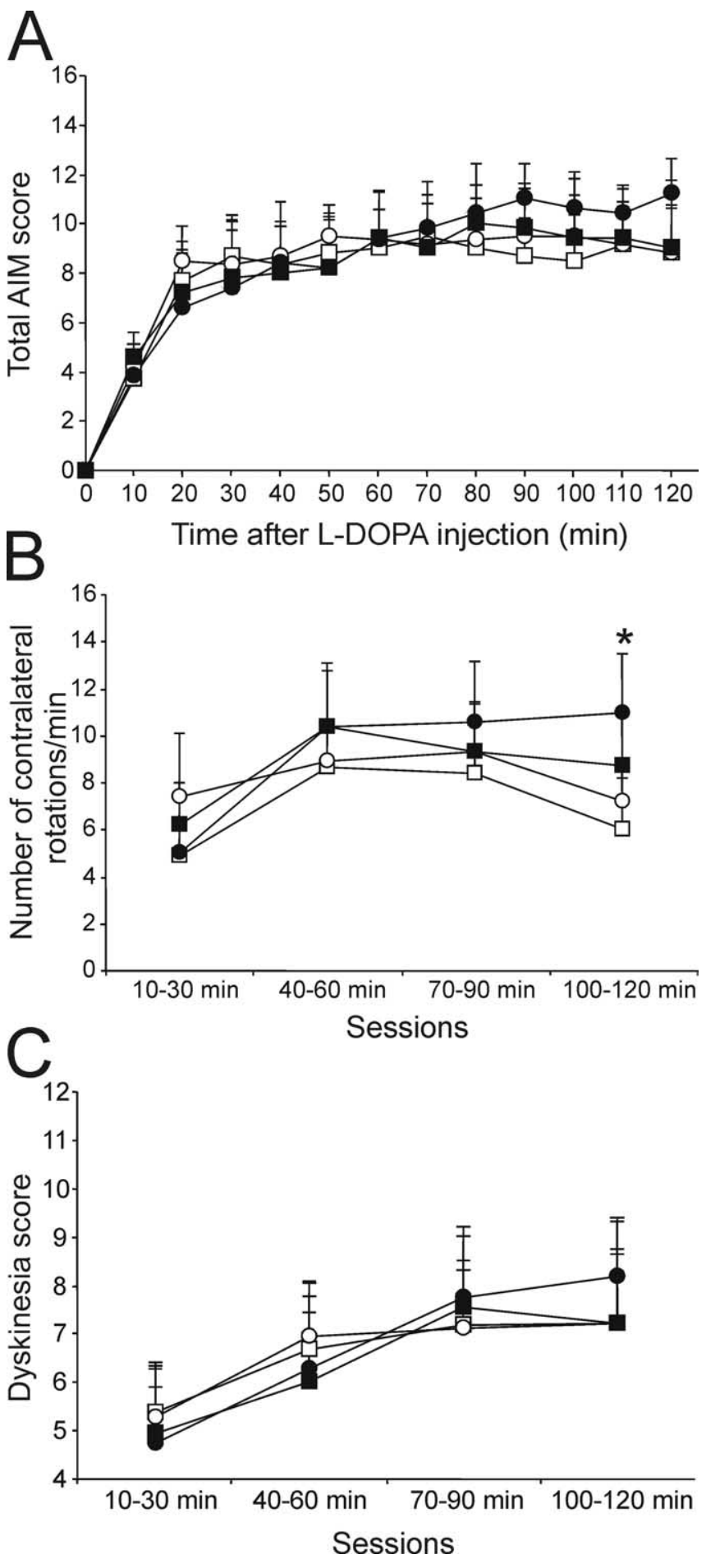

Figure 3. Effects of subthalamic nucleus high-frequency stimulation on L-DOPA-induced AIMs. Analysis of AIMs was performed in the DOPA group at day $14(\square)$ and day $19(\bigcirc)$, corresponding in the DOPA + HFS group to the time points prestimulation ( $\square$ ) and $5 \mathrm{~d}$ of stimulation (O), respectively. A, Time course of the total AIM score (sum of locomotive, axial, orolingual, and forelimb scores, each rated in a scale from 0 to 4; maximum score 16) per monitoring session (1 min every 10 min over 2 h). $\boldsymbol{B}$, Locomotive AIM, expressed in number of contralateral rotations per minute and dyskinesia score $(\boldsymbol{C})$, corresponding to the sum of the axial, orolingual, and forelimb AIM scores (maximum 12). Four windows are considered in the $2 \mathrm{~h}$ monitoring period, each corresponding to the mean of the values obtained in three recording sessions. The data are the means \pm SEM from six L-DOPA and five DOPA plus HFS animals. Paired $t$ test comparisons are performed between day 14 and day 19 values in the DOPA group and between prestimulation and $5 \mathrm{~d}$ stimulation values in the DOPA + HFS group. ${ }^{*} p<0.05$ compared with prestimulation values. the locomotive AIMs, expressed in number of contralateral rotations per min, and the three other AIM subtypes. Figure $3 B$ illustrates the rotational behavior. Significant difference was measured only for the 100-120 min window between prestimulation and $5 \mathrm{~d}$ stimulation values ( $p<0.05$ using paired $t$ test). In fact, at days 14 and 19 of L-DOPA and for prestimulation, the pick of rotations was followed by a decline at 90-120 min, whereas there was a plateau maintained at 100-120 min under stimulation, suggesting that STN-HFS prolonged the rotational behavior. Figure $3 C$ illustrates the dyskinetic behavior, i.e., the sum of axial, orolingual, and forelimb dyskinesias. No significant differences were measured at any windows between day 14 and 19 in the two groups of animals, although poststimulation scores tended to be higher than the prestimulation ones within the same 100-120 min window.

Effects of dyskinesiogenic L-DOPA and chronic HFS of STN, applied separately, successively, or together on markers of striatal cell populations

All of the following results concern the dopamine-depleted striatum. No significant change was measured in the striatum contralateral to surgery in any of the experimental conditions examined.

Preproenkephalin A mRNA levels (Fig. 4)

The expression of PPE was increased by $73 \%$ in the 6-OHDA group compared with controls. This response was not affected in HFS animals but further increased by $27 \%$ in DOPA animals. In the DOPA plus HFS group, the increase in PPE was exacerbated compared with the DOPA group $(+18 \%)$. No L-DOPA-driven increase in PPE was measured in the DOPA/washout group [nonsignificant (NS) compared with 6-OHDA]. In the DOPA/ HFS animals, PPE mRNA expression was not significantly modified compared with 6-OHDA animals.

Preprodynorphin mRNA levels (Fig. 5)

In the 6-OHDA group, PPDyn mRNA levels were decreased compared with controls $(-25 \%)$, but this effect did not reached statistical significance. No significant change was observed in HFS group, whereas DOPA rats showed a dramatic increase both compared with 6-OHDA and with controls $(+540 \%$ and + $392 \%$, respectively). A further increase above DOPA values $(+30 \%)$ was measured in DOPA plus HFS animals. A significant increase in PPDyn was maintained in the DOPA/washout group ( $+94.6 \%$ compared with controls), and a further increase was measured in the DOPA/HFS condition $(+27.6 \%$ compared with L-DOPA/washout group).

\section{Preprotachykinin mRNA levels (Fig. 6)}

PPT mRNA expression was decreased by 33\% in 6-OHDA animals compared with controls. This effect was reversed in DOPA (NS compared with control and $+52 \%$ compared with 6-OHDA) but unaffected in HFS animals. HFS plus DOPA animals showed an increase in PPT above control and DOPA values $(+19 \%$ and $+16 \%$, respectively). PPT mRNA levels in DOPA/ washout and DOPA/HFS groups did not differ from the 6-OHDA condition.

\section{GLT1 mRNA levels (Fig. 7)}

GLT1 mRNA levels were not significantly modified in both 6-OHDA and HFS animals compared with controls but were significantly increased by $28 \%$ in the DOPA ones. The DOPA plus HFS group showed a further increase above DOPA values $(+28.7 \%$ vs DOPA; $+65 \%$ vs controls $)$. No significant differ- 


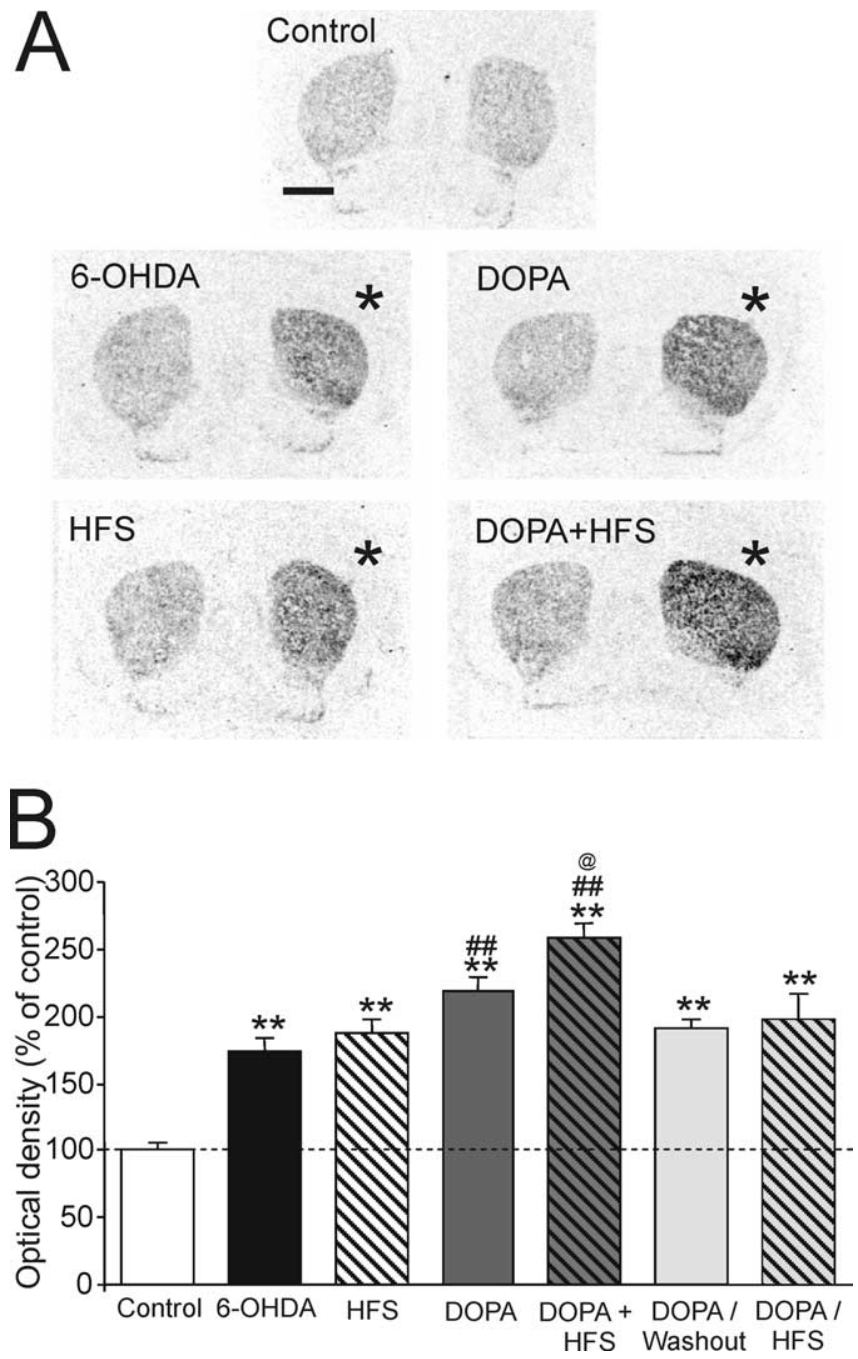

Figure 4. $\quad \boldsymbol{A}, \boldsymbol{B}$, Digitized autoradiographic images $(\boldsymbol{A})$ and quantitative analysis $(\boldsymbol{B})$ showing the effects of subthalamic nucleus high-frequency stimulation and of $\mathrm{L}-\mathrm{DOPA}$ treatment on the dopamine denervation-mediated increase in striatal preproenkephalin mRNA expression. The data presented in the graphs are the means \pm SEM of the optical density values determined from $n$ animals per condition and are expressed as percentages of control. Statistical comparisons are performed using a one-way ANOVA followed by Student-Newman-Keuls test. Analysis included the control, 6-OHDA, HFS, DOPA, and DOPA+HFS groups for the combined treatment condition and the control, 6-OHDA, HFS, DOPA/washout, and DOPA/HFS groups for the successive treatment condition. ${ }^{* *} p<0.01$ compared with control values; $\# p<0.01$ compared with 6-OHDA; ${ }^{@} p<0.05$ compared with DOPA. * Side ipsilateral to surgery. Scale bar, $2 \mathrm{~mm}$.

ences were measured versus controls or 6-OHDA in both the DOPA/washout and the DOPA/HFS groups.

Expression of FosB-like proteins (Fig. 8)

Compared with 6-OHDA, the number of FosB/ $\Delta$ FosB-positive neurons was unaffected in the HFS group but was markedly increased in the DOPA group both in the lateral and the medial parts of the striatum (18-fold and sixfold, respectively). DOPA plus HFS rats showed an additional significant increase versus DOPA in the medial $(+45 \%)$ but not in the lateral part of the striatum. In the DOPA/washout group, the number of FosB/ $\Delta$ FosB-positive neurons was still increased by $\sim 17$-fold and 4.5 fold versus 6-OHDA in the lateral and medial parts of the striatum, respectively. In the DOPA/HFS group, an additional
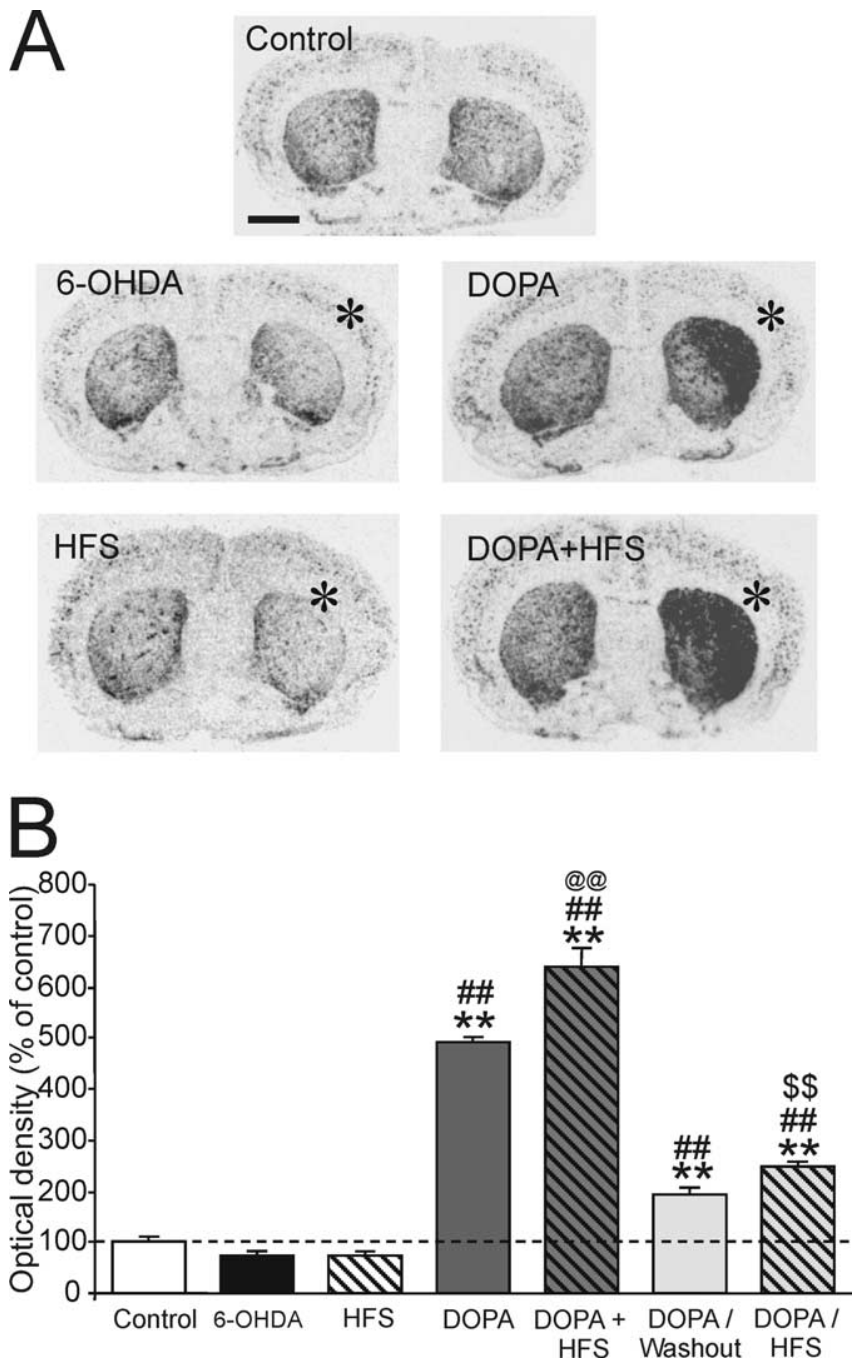

Figure 5. $\quad \boldsymbol{A}, \boldsymbol{B}$, Digitized autoradiographic images $(\boldsymbol{A})$ and quantitative analysis $(\boldsymbol{B})$ showing the effects of subthalamic nucleus high-frequency stimulation and of L-DOPA treatment on striatal preprodynorphin mRNA expression. The data are determined and presented as in Figure 4. ${ }^{* *} p<0.01$ compared with control values; ${ }^{\# \#} p<0.01$ compared with 6-OHDA; ${ }^{\circledR} p<0.01$ compared with DOPA; and ${ }^{\$ \$} p<0.01$ compared with DOPA/washout. *Side ipsilateral to surgery. Scale bar, $2 \mathrm{~mm}$.

significant increase by $55 \%$ versus DOPA/washout was again measured in the medial but not the lateral part of the striatum.

Effects of dyskinesiogenic L-DOPA and chronic HFS of STN, applied separately or together on intraneuronal cytochrome oxidase subunit I mRNA levels in the motor cortex (Fig. 9).

Neurons of layer $\mathrm{V}$ of the motor cortex showed decreased CoI mRNA levels $(\sim 22 \%$; $p<0.05)$ in the 6-OHDA animals. This effect was abolished in the HFS and DOPA plus HFS groups (NS compared with control, $+43.6 \%$ and $+35.8 \%$ compared with 6-OHDA, respectively) but not significantly modified in the DOPA group (NS compared with both control and 6-OHDA animals).

\section{Discussion}

This study shows that STN-HFS has effects per se on neurons of the motor cortex, whereas it acts at striatal levels by modulating L-DOPA effects. These data provide strong evidence that the striatum is a primary site of the interaction between the two treatments. 

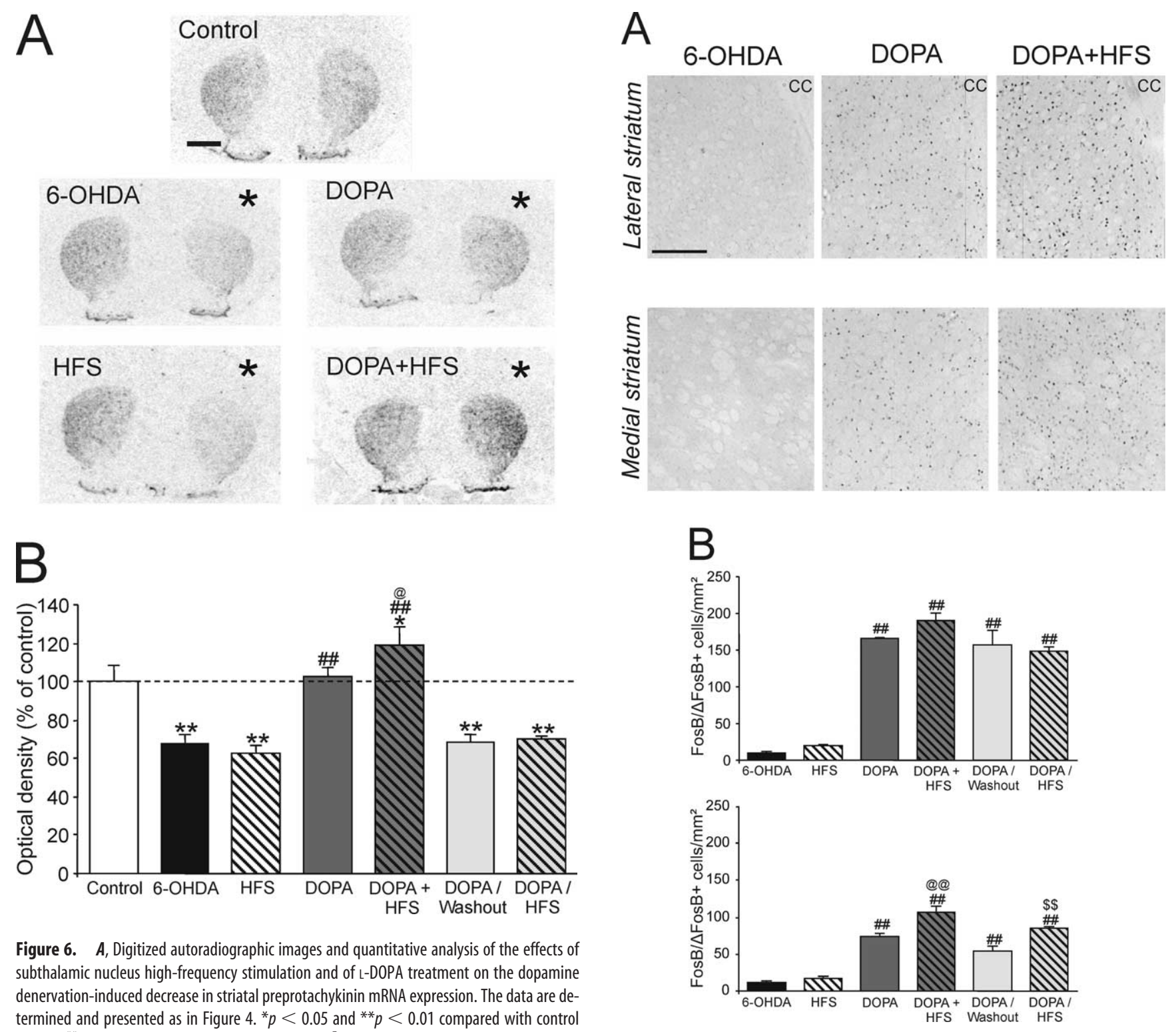

Figure 6. A, Digitized autoradiographic images and quantitative analysis of the effects of subthalamic nucleus high-frequency stimulation and of L-DOPA treatment on the dopamine denervation-induced decrease in striatal preprotachykinin mRNA expression. The data are determined and presented as in Figure $4 .{ }^{*} p<0.05$ and ${ }^{* *} p<0.01$ compared with control values; ${ }^{\# \#} p<0.01$ compared with 6-OHDA; and ${ }^{\circledR} p<0.05$ compared with DOPA. ${ }^{*}$ Side ipsilateral to surgery. Scale bar, $2 \mathrm{~mm}$.

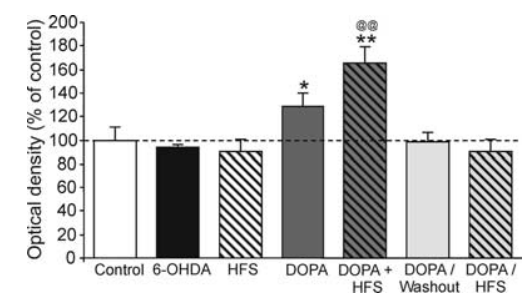

Figure 7. Quantitative analysis of the effects of subthalamic nucleus high-frequency stimulation and of L-DOPA treatment on striatal GLT1 mRNA expression. The data are determined and presented as in Figure $4 .{ }^{*} p<0.05$ and $^{* *} p<0.01$ compared with control values; ${ }^{@ @ ~} p<0.01$ compared with DOPA.

Cellular effects of dopamine denervation and dyskinesiogenic L-DOPA treatment

Our study shows that neuronal metabolic activity, as assessed by CoI mRNA levels, is decreased in layer $\mathrm{V}$ of motor cortical areas in rats with extensive lesion of nigral dopamine neurons, which extends the previous finding of decreased metabolic activity of

Figure 8. $\boldsymbol{A}, \boldsymbol{B}$, Representative photomicrographs of brain sections $(\boldsymbol{A})$ and quantitative analysis $(\boldsymbol{B})$ showing the effects of subthalamic nucleus high-frequency stimulation and of L-DOPA treatment on FosB/ $\triangle$ FosB immunoreactivity in the lateral and medial parts of the striatum ipsilateral to surgery. The data presented in the graphs are expressed in number of FosB/ $\Delta$ FosB-immunoreactive neurons per square millimeter and are the means \pm SEM from $n$ animals per condition. ${ }^{\# \#} p<0.01$ compared with 6-OHDA; ${ }^{@} p<0.01$ compared with DOPA; and ${ }^{\$ \$} p<0.01$ compared with DOPA/washout. Scale bar, $250 \mu \mathrm{m}$. cc, Corpus callosum.

corticosubthalamic neurons (Orieux et al., 2002). Interestingly, such decrease has also been reported to occur in a model of partial bilateral lesion and to correlate with the expression of akinetic deficits (Oueslati et al., 2005). We further found that this cortical response is not significantly modified $12 \mathrm{~h}$ after the end of chronic dyskinesiogenic L-DOPA treatment, which does not exclude possible transient changes under "on" L-DOPA state.

In the striatum, all of the cellular effects of the dopamine lesion and of L-DOPA treatment reported here are in agreement with previous literature data. L-DOPA treatment reversed the lesion-induced decrease in PPT, further increased PPE, induced upregulation of PPDyn and GLT1 (Cenci et al. 1998; Henry et al., 1999, 2003; Calon et al., 2000, 2002; Zeng et al., 2000; Carta et al., 2002; Tel et al., 2002; Robelet et al., 2004), and increased FosB/ 


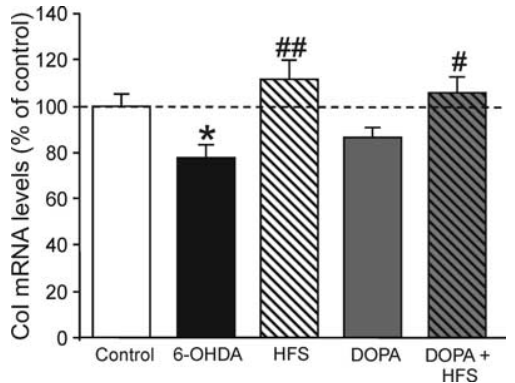

Figure 9. Quantitative analysis of the effects of subthalamic nucleus high-frequency stimulation and of L-DOPA treatment on Col mRNA expression in the neurons of layer $V$ of the motor cortex. The data are the means \pm SEM of the number of silver grains per cell determined in each experimental condition and are expressed as percentages of control. Statistical comparisons are performed using a one-way ANOVA followed by Student-Newman-Keuls test. ${ }^{*} p<0.05$ compared with control values; $\#<0.05$ and ${ }^{\# \#} p<0.01$ compared with 6-0HDA.

$\Delta$ FosB immunoreactivity (Andersson et al., 1999). PPDyn mRNA and FosB $/ \Delta$ FosB immunoreactivity remained significantly elevated after $5 \mathrm{~d}$ of L-DOPA withdrawal. $\Delta$ FosB is a unique transcription factor that plays an essential role in longterm adaptive changes in the brain (McClung et al., 2004). The maintenance of concomitant upregulation of FosB $/ \Delta$ FosB and of PPDyn is in agreement with previous data showing that $\Delta \mathrm{FosB}$, together with structural and synaptic plasticity markers, is preferentially induced in striatal PPDyn-containing neurons (Sgambato-Faure et al., 2005) and that the accumulation of FosBlike proteins induced by chronic L-DOPA is a particularly stable phenomenon, underlying sustained effects on the expression of their target genes, notably PPDyn (Andersson et al., 2003). We show that, contrarily to PPDyn, no effect of chronic L-DOPA treatment on striatal PPT, PPE, and GLT1 are observed after the $5 \mathrm{~d}$ washout period, suggesting that different pathways are involved in the responses of these markers to L-DOPA. Interestingly, the coordinated changes in the gene expression of the glial glutamate transporter GLT1 and PPE suggest that the responses of PPE-containing neurons to L-DOPA may be preferentially linked to glutamate-mediated mechanisms involving changes in astrocyte glutamate metabolism.

The possible implication of the L-DOPA-induced changes in the different striatal markers examined on the electrophysiological activities and integrative functions of striatal cells is not known. However, because AMPA and NMDA receptor subunits are candidate target genes for $\Delta$ FosB (McClung et al., 2004), and the efficiency of glutamate transmission critically depends on glial glutamate metabolism, it is tempting to relate the induction of $\Delta$ FosB and overexpression of GLT1 to pathological striatal synaptic plasticity. For instance, LIDs have been recently linked to increased spontaneous activity (Gubellini et al., 2006) and impaired depotentiation at striatal glutamatergic synapses (Picconi et al., 2003), as well as to changes in NMDA receptor subunit composition, phosphorylation, subcellular localization (Gardoni et al., 2006), and complex formed with $D_{1}$ dopamine receptor (Fiorentini et al., 2006).

\section{Behavioral and cellular effects of prolonged STN-HFS}

STN-HFS at high intensity can induce per se dyskinetic movements. Here, we examined the effects of prolonged STN-HFS when applied at low intensity, providing antiparkinsonian benefits without inducing any subtypes of AIMs. Our behavioral study using the cylinder test shows that STN-HFS progressively relieves akinesia, $4-5 \mathrm{~d}$ of continuous stimulation being required for complete recovery of double contacts. Such delay could be related to the robustness of the cylinder test, which assesses the spontaneous forelimb use, because rapid antiparkinsonian benefits have been reported using other motor tasks in rats (Darbaky et al., 2003; Shi et al., 2006). However, it complies with the observation that the maximum beneficial effect of STN-HFS on bradykinesia/ akinesia in PD patients may require hours to days, whereas other symptoms alleviate within minutes (Krack et al., 2002).

At the cellular level, we show that STN-HFS reverses the dopamine lesion-induced decrease in CoI mRNA expression in the motor cortex, which could contribute to the anti-akinetic action of this surgical treatment. This finding can be compared with recent data showing that STN-HFS $(2-4 \mathrm{~h})$ induces immediateearly gene expression in the motor cortex (Schulte et al., 2006). The cortical activation could be the consequence of an excitation, and additional antidromic invasion, of corticosubthalamic axons, because the areas examined are known to send projections to STN (Orieux et al., 2002), or be linked to the rapid normalization of the cellular changes in the basal ganglia output structures (Salin et al., 2002; Tai et al., 2003; Bacci et al., 2004; Degos et al., 2005). In the striatum, we confirm our previous finding that prolonged STN-HFS per se does not modify the dopamine lesion-induced changes in PPE and PPT mRNA levels (Bacci et al., 2004), and we show that it does not modify either the postlesional decrease in PPD mRNA levels nor affected GLT1 gene expression and FosB/ $\Delta$ FosB immunoreactivity. The lack of effects on striatal cell markers complies with the electrophysiological recordings showing no major change in striatal cell firing (Shi et al., 2006) and suggests that the striatum may not be the main site of the anti-akinetic action of STN-HFS, at least under extensive dopamine denervation conditions.

\section{Interactions between prolonged STN-HFS and dyskinesiogenic L-DOPA treatment}

Our study shows that STN-HFS does not reduce but rather tends to increase LID. This increasing effect is, however, moderate, mostly observable at the end of the monitoring period of $2 \mathrm{~h}$ after L-DOPA injection. This finding argues against a direct antidyskinetic effect of STN-HFS and supports the view that relief of LID by HFS of STN depends on postoperative reduction of dopaminergic medication (Krack et al., 2002; Follett, 2004; Russmann et al., 2004). In contrast with its weak impact on LID, STN-HFS significantly interferes with the cellular effects of both associated and previous L-DOPA treatment at striatal level. When associated with L-DOPA, STN-HFS induced an additional increase in all of the markers examined, demonstrating a potentiation by HFS of the L-DOPA effects. Interestingly, HFS subsequent to L-DOPA treatment had no effect on the markers whose expression, after L-DOPA withdrawal, did not differ from untreated lesioned rats, but exacerbated the responses maintained after L-DOPA washout, i.e., FosB induction and upregulation of PPDyn gene expression. These data suggest that this surgical treatment acts specifically on the examined markers through L-DOPA-dependent signaling pathways. Previous studies have emphasized the causal role for striatal FosB induction in the development of LID and have suggested that the sustained elevation of this transcription factor and target gene expression after L-DOPA withdrawal maintains the sensitization to L-DOPA responsible for LID (Andersson et al., 1999, 2003). Because STNHFS exacerbates those cellular responses, it would be expected to have a higher impact on LID than that found here. It could be that the effect on LID is limited because most of the animals already show severe dyskinesias or because STN-HFS acts on the dura- 
tion rather than on the severity of LID. It also could be that STN-HFS differentially interferes with L-DOPA-mediated responses in basal ganglia structures downstream the striatum, such as the internal globus pallidus, whose HFS has a direct antidyskinetic effect in PD patients (Follett, 2004).

\section{Possible neural substrates of the striatal interaction between STN-HFS and L-DOPA}

Here we show that STN-HFS has no effects per se on the examined striatal markers but exacerbates the effects of L-DOPA, whereas STN lesion has been reported to reverse the increase in striatal PPE induced by dopamine lesion (Delfs et al., 1995; Bacci et al., 2004) and to efficiently limit the further increase produced by L-DOPA (Perier et al., 2003). This comparison indicates that the two surgical approaches, although providing antiparkinsonian benefits, induce different rearrangements in the striatum underlying different responsiveness to L-DOPA.

The pathways underlying such rearrangements remain a matter of concern. Our knowledge on the direct input from STN to striatum is poor, the data available showing moderate projections to the striatum (Kita and Kitai, 1987) whose cellular targets and functional implication remain unknown. There is a crucial need to re-examine in more details the subthalamostriatal projections and determine whether STN-HFS modifies their organization or functional strength. In contrast, numerous studies have involved changes in corticostriatal glutamatergic transmission as a mediator of the effects of the dopamine lesion and L-DOPA treatment on certain populations of striatal neurons, notably of the changes in PPE gene expression. For instance, dopamine lesion is known to induce an increase in striatal glutamate transmission, and we recently provided evidence for an additional increase in L-DOPAtreated dyskinetic rats (Gubellini et al., 2006). Consistently, treatments with glutamate antagonists reduce both the increase in striatal PPE induced by dopamine lesion (Hajji et al., 1996) and the additional increase elicited by L-DOPA (Perier et al., 2002) as well as LID. However, striatal glutamate synaptic transmission is unlikely to mediate the cellular effects of STN-HFS reported here. Indeed, whereas STN-HFS is presently shown to exacerbate L-DOPA-induced increase in PPE, we found that this stimulation efficiently depresses spontaneous striatal glutamatergic transmission both in parkinsonian rats and L-DOPA-treated dyskinetic rats (Gubellini et al., 2006). Modulation of the dopamine transmission is another possible mechanism involved in the interaction between STN-HFS and L-DOPA medication. positron emission tomography (PET) studies in PD patients have shown that STN-HFS does not produce significant striatal DA release (Abosch et al., 2003; Hilker et al., 2003; Strafella et al., 2003; Thobois et al., 2003), suggesting that striatal dopamine is not a crucial mediator of the antiparkinsonian action of STN-HFS. However, there is accumulating evidence that STN-HFS increases striatal dopamine efflux and metabolism in normal rats or rats with partial dopamine lesion (Bruet et al., 2001; Meissner et al., 2003; Lee et al., 2006). In addition, recent PET data have shown that STN-HFS in PD patients attenuates the L-DOPAinduced fluctuations of striatal DA levels, with possible involvement in the alleviation of motor fluctuation (Nimura et al., 2005). These data suggest that modulation of DA transmission could be involved in the effects of STN-HFS when dopamine transmission is still efficient or restored by L-DOPA. It would be now of primary interest to determine the impact of STN-HFS on striatal dopamine turnover and transmission, notably at dopamine receptor level, in L-DOPA-treated parkinsonian rats either dyskinetic or not.
In conclusion, our study provides the first evidence that STNHFS exacerbates the cellular changes produced in the striatum by dyskinesiogenic L-DOPA treatment, including the responses that are sustained after L-DOPA withdrawal, i.e., the induction of FosB $/ \Delta$ FosB-like proteins and upregulation of the target gene PPDyn, which are thought to maintain the sensitization to L-DOPA responsible for LID. These findings lead to a reappraisal of the impact of this surgical treatment on the overall corticobasal gangliacortical loop depending on dopamine tone, opening new perspectives for the fine-tuning of combined HFS and L-DOPA therapy.

\section{References}

Abosch A, Kapur S, Lang AE, Hussey D, Sime E, Miyasaki J, Houle S, Lozano AM (2003) Stimulation of the subthalamic nucleus in Parkinson's disease does not produce striatal dopamine release. Neurosurgery 53:1095-1102.

Andersson M, Hilbertson A, Cenci MA (1999) Striatal fosB expression is causally linked with 1-DOPA-induced abnormal involuntary movements and the associated upregulation of striatal prodynorphin mRNA in a rat model of Parkinson's disease. Neurobiol Dis 6:461-474.

Andersson M, Westin JE, Cenci MA (2003) Time course of striatal DeltaFosB-like immunoreactivity and prodynorphin mRNA levels after discontinuation of chronic dopaminomimetic treatment. Eur J Neurosci 17:661-666.

Bacci JJ, Absi el H, Manrique C, Baunez C, Salin P, Kerkerian-Le Goff L (2004) Differential effects of prolonged high frequency stimulation and of excitotoxic lesion of the subthalamic nucleus on dopamine denervation-induced cellular defects in the rat striatum and globus pallidus. Eur J Neurosci 20:3331-3341.

Benabid AL, Krack PP, Benazzouz A, Limousin P, Koudsie A, Pollak P (2000) Deep brain stimulation of the subthalamic nucleus for Parkinson's disease: methodologic aspects and clinical criteria. Neurology 55:S40-S44.

Boulet S, Lacombe E, Carcenac C, Feuerstein C, Sgambato-Faure V, Poupard A, Savasta M (2006) Subthalamic stimulation-induced forelimb dyskinesias are linked to an increase in glutamate levels in the substantia nigra pars reticulata. J Neurosci 8:10768-10776.

Bruet N, Windels F, Bertrand A, Feuerstein C, Poupard A, Savasta M (2001) High frequency stimulation of the subthalamic nucleus increases the extracellular contents of striatal dopamine in normal and partially dopaminergic denervated rats. J Neuropathol Exp Neurol 60:15-24.

Bruet N, Windels F, Carcenac C, Feuerstein C, Bertrand A, Poupard A, Savasta M (2003) Neurochemical mechanisms induced by high frequency stimulation of the subthalamic nucleus: increase of extracellular striatal glutamate and GABA in normal and hemiparkinsonian rats J Neuropathol Exp Neurol 62:1228-1240.

Calon F, Grondin R, Morissette M, Goulet M, Blanchet PJ, Di Paolo T, Bedard PJ (2000) Molecular basis of levodopa-induced dyskinesias. Ann Neurol 47[4 Suppl 1]:S70-S78.

Calon F, Birdi S, Rajput AH, Hornykiewicz O, Bedard PJ, Di Paolo T (2002) Increase of preproenkephalin mRNA levels in the putamen of Parkinson disease patients with levodopa-induced dyskinesias. J Neuropathol Exp Neurol 61:186-196.

Calon F, Rajput AH, Hornykiewicz O, Bedard PJ, Di Paolo T (2003) Levodopa-induced motor complications are associated with alterations of glutamate receptors in Parkinson's disease. Neurobiol Dis 14:404-416.

Carta AR, Pinna A, Cauli O, Morelli M (2002) Differential regulation of GAD67, enkephalin and dynorphin mRNAs by chronic-intermittent L-dopa and A2A receptor blockade plus L-dopa in dopamine-denervated rats. Synapse 44:166-174.

Cenci MA (2002) Transcription factors involved in the pathogenesis of L-DOPA-induced dyskinesia in a rat model of Parkinson's disease. Amino Acids 23:105-109.

Cenci MA, Lee CS, Bjorklund A (1998) L-DOPA-induced dyskinesia in the rat is associated with striatal overexpression of prodynorphin- and glutamic acid decarboxylase mRNA. Eur J Neurosci 10:2694-2706.

Chase TN, Oh JD (2000) Striatal mechanisms and pathogenesis of parkinsonian signs and motor complications. Ann Neurol 47:S122-S130.

Darbaky Y, Forni C, Amalric M, Baunez C (2003) High frequency stimulation of the subthalamic nucleus has beneficial antiparkinsonian effects on motor functions in rats, but less efficiency in a choice reaction time task. Eur J Neurosci 18:951-956. 
Degos B, Deniau JM, Thierry AM, Glowinski J, Pezard L, Maurice N (2005) Neuroleptic-induced catalepsy: electrophysiological mechanisms of functional recovery induced by high-frequency stimulation of the subthalamic nucleus. J Neurosci 25:7687-7696.

De Groot (1959) The rat forebrain in stereotaxic coordinates. AFD Natuurkunde N. V. Noord-Hallandsche Wetgevers Maatschappij. Amsterdam: Verhandelingen der Koninklijke Nederlandse Akademic van Wetenschappen.

Delfs JM, Ciaramitaro VM, Parry TJ, Chesselet MF (1995) Subthalamic nucleus lesions: widespread effects on changes in gene expression induced by nigrostriatal dopamine depletion in rats. J Neurosci 15:6562-6575.

Fiorentini C, Rizzetti MC, Busi C, Bontempi S, Collo G, Spano P, Missale C (2006) Loss of synaptic D1 dopamine/N-methyl-D-aspartate glutamate receptor complexes in L-DOPA-induced dyskinesia in the rat. Mol Pharmacol 69:805-812.

Follett KA (2004) Comparison of pallidal and subthalamic deep brain stimulation for the treatment of levodopa-induced dyskinesias. Neurosurg Focus 17:E3.

Garcia L, D’Alessandro G, Bioulac B, Hammond C (2005) High-frequency stimulation in Parkinson's disease: more or less? Trends Neurosci 28:209-216.

Gardoni F, Picconi B, Ghiglieri V, Polli F, Bagetta V, Bernardi G, Cattabeni F, Di Luca M, Calabresi P (2006) A critical interaction between NR2B and MAGUK in L-DOPA induced dyskinesia. J Neurosci 26:2914-2922.

Gubellini P, Eusebio A, Oueslati A, Melon C, Kerkerian-Le Goff L, Salin P (2006) Chronic high-frequency stimulation of the subthalamic nucleus and L-DOPA treatment in experimental parkinsonism: effects on motor behaviour and striatal glutamate transmission. Eur J Neurosci 24:1802-1814.

Hajji MD, Salin P, Kerkerian-Le Goff L (1996) Chronic dizocilpine maleate (MK-801) treatment suppresses the effects of nigrostriatal dopamine deafferentation on enkephalin but not on substance $\mathrm{P}$ expression in the rat striatum. Eur J Neurosci 8:917-926.

Henry B, Crossman AR, Brotchie JM (1999) Effect of repeated L-DOPA, bromocriptine, or lisuride administration on preproenkephalin-A and preproenkephalin-B mRNA levels in the striatum of the 6-hydroxydopamine-lesioned rat. Exp Neurol 155:204-220.

Henry B, Duty S, Fox SH, Crossman AR, Brotchie JM (2003) Increased striatal pre-proenkephalin B expression is associated with dyskinesia in Parkinson's disease. Exp Neurol Oct 183:458-468.

Hilker R, Voges J, Ghaemi M, Lehrke R, Rudolf J, Koulousakis A, Herholz K, Wienhard K, Sturm V, Heiss WD (2003) Deep brain stimulation of the subthalamic nucleus does not increase the striatal dopamine concentration in parkinsonian humans. Mov Disord 18:41-48.

Kita H, Kitai ST (1987) Efferent projections of the subthalamic nucleus in the rat: light and electron microscopic analysis with the PHA-L method. J Comp Neurol 260:435-452.

Krack P, Fraix V, Mendes A, Benabid AL, Pollak P (2002) Postoperative management of subthalamic nucleus stimulation for Parkinson's disease. Mov Disord 17 [Suppl 3]:S188-S197.

Lee KH, Blaha CD, Harris BT, Cooper S, Hitti FL, Leiter JC, Roberts DW, Kim U (2006) Dopamine efflux in the rat striatum evoked by electrical stimulation of the subthalamic nucleus: potential mechanism of action in Parkinson's disease. Eur J Neurosci 23:1005-1014.

Lievens JC, Salin P, Nieoullon A, Kerkerian-Le Goff L (2001) Nigrostriatal denervation does not affect glutamate transporter mRNA expression but subsequent levodopa treatment selectively increases GLT1 mRNA and protein expression in the rat striatum. J Neurochem 79:893-902.

McClung CA, Ulery PG, Perrotti LI, Zachariou V, Berton O, Nestler EJ (2004) DeltaFosB: a molecular switch for long-term adaptation in the brain. Brain Res Mol Brain Res 132:146-154.

McIntyre CC, Savasta M, Kerkerian-Le Goff L, Vitek JL (2004) Uncovering the mechanism(s) of action of deep brain stimulation: activation, inhibition, or both. Clin Neurophysiol 115:1239-1248.

Meissner W, Harnack D, Reese R, Paul G, Reum T, Ansorge M, Kusserow H, Winter C, Morgenstern R, Kupsch A (2003) High-frequency stimulation of the subthalamic nucleus enhances striatal dopamine release and metabolism in rats. J Neurochem 85:601-609.

Nestler EJ, Kelz MB, Chen J (1999) DeltaFosB: a molecular mediator of long-term neural and behavioral plasticity. Brain Res 835:10-17.

Nimura T, Yamaguchi K, Ando T, Shibuya S, Oikawa T, Nakagawa A, Shirane R, Itoh M, Tominaga T (2005) Attenuation of fluctuating striatal synap- tic dopamine levels in patients with Parkinson disease in response to subthalamic nucleus stimulation: a positron emission tomography study. J Neurosurg 103:968-973.

Olanow CW (2002) Surgical therapy for Parkinson's disease. Eur J Neurol 9 [Suppl 3]:31-39.

Orieux G, Francois C, Feger J, Hirsch EC (2002) Consequences of dopaminergic denervation on the metabolic activity of the cortical neurons projecting to the subthalamic nucleus in the rat. J Neurosci 22:8762-8770.

Oueslati A, Breysse N, Amalric M, Kerkerian-Le Goff L, Salin P (2005) Dysfunction of the cortico-basal ganglia-cortical loop in a rat model of early parkinsonism is reversed by metabotropic glutamate receptor 5 antagonism. Eur J Neurosci 22:2765-2774.

Paxinos G, Watson C (1986) The rat brain in stereotaxic coordinates. New York: Academic.

Perier C, Marin C, Bonastre M, Tolosa E, Hirsch EC (2002) AMPA receptor antagonist LY293558 reverses preproenkephalin mRNA overexpression in the striatum of 6-OHDA-lesioned-rats treated with L-dopa. Eur J Neurosci 16:2236-2240.

Perier C, Marin C, Jimenez A, Bonastre M, Tolosa E, Hirsch EC (2003) Effect of subthalamic nucleus or entopeduncular nucleus lesion on levodopa-induced neurochemical changes within the basal ganglia and on levodopa-induced motor alterations in 6-hydroxydopamine-lesioned rats. J Neurochem 86:1328-1337.

Perlmutter JS, Mink JW (2006) Deep brain stimulation. Annu Rev Neurosci 29:229-257.

Perrotti LI, Hadeishi Y, Ulery PG, Barrot M, Monteggia L, Duman RS, Nestler EJ (2004) Induction of deltaFosB in reward-related brain structures after chronic stress. J Neurosci 24:10594-10602.

Picconi B, Centonze D, Hakansson K, Bernardi G, Greengard P, Fisone G, Cenci MA, Calabresi P (2003) Loss of bidirectional striatal synaptic plasticity in L-DOPA-induced dyskinesia. Nat Neurosci 6:501-506.

Robelet S, Melon C, Guillet B, Salin P, Kerkerian-Le Goff L (2004) Chronic L-DOPA treatment increases extracellular glutamate levels and GLT1 expression in the basal ganglia in a rat model of Parkinson's disease. Eur J Neurosci 20:1255-1266.

Russmann H, Ghika J, Combrement P, Villemure JG, Bogousslavsky J, Burkhard PR, Vingerhoets FJ (2004) L-dopa-induced dyskinesia improvement after STN-DBS depends upon medication reduction. Neurology 63:153-155.

Salin P, Manrique C, Forni C, Kerkerian-Le Goff L (2002) High frequency stimulation of the subthalamic nucleus selectively reverses dopamine denervation-induced cellular defects in the output structures of the basal ganglia in the rat. J Neurosci 22:5137-5148.

Schulte T, Brecht S, Herdegen T, Illert M, Mehdorn HM, Hamel W (2006) Induction of immediate early gene expression by high-frequency stimulation of the subthalamic nucleus in rats. Neuroscience 138:1377-1385.

Sgambato-Faure V, Buggia V, Gilbert F, Levesque D, Benabid AL, Berger F (2005) Coordinated and spatial upregulation of arc in striatonigral neurons correlates with L-dopa-induced behavioral sensitization in dyskinetic rats. J Neuropathol Exp Neurol 64:936-947.

Shi LH, Luo F, Woodward DJ, Chang JY (2006) Basal ganglia neural responses during behaviorally effective deep brain stimulation of the subthalamic nucleus in rats performing a treadmill locomotion test. Synapse 59:445-457.

Strafella AP, Sadikot AF, Dagher A (2003) Subthalamic deep brain stimulation does not induce striatal dopamine release in Parkinson's disease. NeuroReport 14:1287-1289.

Tai CH, Boraud T, Bezard E, Bioulac B, Gross C, Benazzouz A (2003) Electrophysiological and metabolic evidence that high-frequency stimulation of the subthalamic nucleus bridles neuronal activity in the subthalamic nucleus and the substantia nigra reticulata. FASEB J 17:1820-1830.

Tel BC, Zeng BY, Cannizzaro C, Pearce RK, Rose S, Jenner P (2002) Alterations in striatal neuropeptide mRNA produced by repeated administration of L-DOPA, ropinirole or bromocriptine correlate with dyskinesia induction in MPTP-treated common marmosets. Neuroscience 115:1047-1058.

Thobois S, Fraix V, Savasta M, Costes N, Pollak P, Mertens P, Koudsie A, Le Bars D, Benabid AL, Broussolle E (2003) Chronic subthalamic nucleus stimulation and striatal D2 dopamine receptors in Parkinson's disease-a [11C]-raclopride PET study. J Neurol 250:1219-1223.

Zeng BY, Pearce RK, MacKenzie GM, Jenner P (2000) Alterations in preproenkephalin and adenosine-2a receptor mRNA, but not preprotachykinin mRNA correlate with occurrence of dyskinesia in normal monkeys chronically treated with L-DOPA. Eur J Neurosci 12:1096-1104. 